Between psychopathology and inclusion the challenging collaboration between educational psychologists and child psychiatrists

Hamre, Bjørn Frithiof; Hedegaard-Sørensen, Lotte; Langager, Søren

Published in:

International Journal of Inclusive Education

DOI:

10.1080/13603116.2017.1395088

Publication date:

2018

Document version

Peer reviewed version

Citation for published version (APA):

Hamre, B. F., Hedegaard-Sørensen, L., \& Langager, S. (2018). Between psychopathology and inclusion: the challenging collaboration between educational psychologists and child psychiatrists. International Journal of Inclusive Education, 22(6), 655-670. [6]. https://doi.org/10.1080/13603116.2017.1395088 


\section{Between psychopathology and inclusion: the challenging collaboration between educational psychologists and child psychiatrists}

Bjørn Hamre, Lotte Hedegaard-Sørensen, and Søren Langager

Paper submitted to: International Journal of Inclusive Education

Bjørn Hamre, University of Copenhaven, Copenhagen, Denmark

hamre@hum.ku.dk

Keywords: inclusive schooling, collaboration, diagnosis, psychopathology, educational psychology, child psychiatry, didactics.

It seems to me that it's all about the definition of power, and it's about professional imperialism. (A psychologist, commenting upon collaboration between psychologists and psychiatrists)

This article reports on a Danish study on interprofessional collaboration between child psychiatrists and educational psychologists concerning children who are categorised as being at risk. Methodologically, the analysis is grounded in qualitative interviews with psychologists. A Foucauldian approach is applied to narratives and experiences that occur within these interviews concerning external collaboration with child psychiatrists. The article is informed by the research tradition that has problematised the significance of psychiatry and diagnoses in the field of special needs education and social pedagogy. We thus enquire into how the rise of diagnostics and medicalisation affects our understanding of children's difficulties.

We discuss a paradox that is present in Denmark and other countries. As educational policies emphasise inclusion, the field of schooling experiences a huge rise in children with medical diagnoses. We argue that diagnostic knowledge is itself an insufficient basis for action and must be considered in relation to teachers' overall training and teachers' situated professionalism.

\section{Background}

The Danish school system has developed an international reputation for referring an unusually large number of students to segregated settings. During the 2000s, the spending on special education increased to such an extent that it accounted for a third of the total annual schools expenditure. In the years after 2010, and especially following a comprehensive school reform in 2014, special educational practices changed radically. The national policy of more inclusive schools has the led to a two-thirds reduction in the number of students in general special education by changing the 
students' legal status from having 'special educational needs' to being 'ordinary'. The long-term aim is to halve the number of students referred to segregated settings, particularly students with intellectual or physical disabilities or psychiatric diagnoses such as ADHD and ASD (Langager 2014). This policy appears to be on a collision course with the rising interest in psychiatric diagnoses and the rapid increase in the number of children encompassed by the child and youth psychiatric assessment. In the past, such children were assigned to special educational settings with adapted physical facilities and courses. This clash between traditions of exclusion (psychiatric assessments) and inclusion (political demands) has led to an increase in students with psychiatric diagnoses who are taking part in the ordinary school environment. The situation has set a new agenda for traditional educational-psychological assessment and counselling work in local schools, which in Denmark is called Educational Psychological Counselling (Padagogisk Psykologisk Rådgivning, or simply PPR).

The changing conditions for PPR offices become evident in the changing demarcations between child psychiatry and educational psychology, with child psychiatry seeming to gain ground alongside the boom in the number of children and young people who receive psychiatric diagnoses, both in Denmark and internationally. In the Danish context there are major differences between the professional traditions of child psychiatry and adult psychiatry. Varied discursive struggles surrounding hospital psychiatry and social psychiatry characterise the adult field, while child psychiatry has experienced less professional turbulence. In general, Danish psychiatry is dominated by traditional biomedical understandings, and its encounter with the huge controversies that are rocking the wider psychiatric profession are evident primarily in debates concerning medicalisation and the use of drugs, with Peter Gøtzsche serving as the 'enfant terrible' in the national debate on the impact of using drugs in psychiatry (e.g. Gøtzsche 2015). Recently, Benny Lihme (2017), writing in a Danish journal, added another critical voice to the discussion. Lihme noted that it was remarkable, that although 'postpsychiatry' had been launched on the international scene over fifteen years previosuly (Bracken and Thomas 2001) and had been followed by the 'critical psychiatric' wave (criticising the dominance of a $19^{\text {th }}$-century biomedical idiom) (Bracken et al. 2012), "The past 30 years have produced no discoveries leading to major changes in psychiatric practice" (Priebe, Burns \& Craig 2013, p. 319), and critical discussions are largely absent from debates concerning psychiatry in Denmark (Lihme 2017).

In parallel, educational psychology has shifted from a culture of testing and troubleshooting towards more attention to a child's environment and socioemotional factors, mostly due to the national political agenda of inclusion. International research and debates within 'critical educational psychology' (e.g. Corcoran ed. 2014) seem to have had very little impact. This may partly be a underlying explanation for some of the findings in the empirical study highlighting why the professional development of educational psychology is challenged by the growing dominance of child psychiatry. Educational psychological counselling offices (PPR) today can thus be characterised as being in an ambivalent situation because they are obliged to achieve an inclusive agenda relative to the school system on the one hand yet must cope with an increasing number of students with psychiatric diagnoses on the other. 
This article is divided into five sections. First, we identify the trends in inclusive practices and diagnostic culture, both internationally and in Denmark following the comprehensive school reform. Second, we flesh out how this diagnostic culture relates to the international understanding of psychopathology in schooling. Third, we introduce the analysis' theoretical position and methodology. Fourth, we present the empirical analysis. Fifth, we discuss the ambivalence of the inclusive agenda and the psychiatric challenge of psychopathology. This is followed by a conclusion.

\section{Trends in inclusion practices and diagnostic cultures in schools}

Sociological critiques of special needs education have emphasised the problematic aspects of segregated provision: injustice, marginalisation, stigmatisation, and exclusion (e.g. Booth \& Ainscow 1998; Skrtic 1999; Slee 2011). The current debate on special needs education and inclusive education is aligned with this critique and focuses on teaching to diversity (Tomlinson 2003). The emphasis is on teachers' ability to make sense of individuals' differences in their teaching, without relying on specific disability categories for teaching strategies. The question about differences between students in school is how these differences are understood and what difference they make for teaching.Inclusive schooling is on the international political agenda. However, despite commitments to this agenda, research suggests that special education is unlikely to disappear (Tomlinson 2013). Inclusive policies coexist alongside an extensive and expanded special educational needs industry (SEN industry). The SEN industry has grown because of parental desire for their children to be resourced on the basis of medical or therapeutic 'diagnoses', the usefulness of excluding troublesome students from the analysis in an environment in which teachers are constantly encouraged to 'raise standards', and the desire of professional specialists to expand their clientele (Tomlinson 2013). Furthermore, exclusion processes within the wider society present obstacles for disabled peoples' access to education, citizenship, and ultimately inclusion in a broader sense (Slee 2013). We argue, based on our empirical study that the dominance of psychiatric knowledge in the interdisciplinary collaboration between psychologists and psychiatrists leads to an emphasis on medical and clinical diagnostic interpretations of children's difficulties. This have consequences for psychologists working in schools and thus for the practice of teaching children in inclusive learning environments. Teachers situated professionalism (HedegaardSørensen \& Tetler 2011 ; 2016) in the practice of teaching is not diagnostic prescriptive and thus not generated from medical diagnosis.

\section{Psychopathology in education}

We align our research with previous studies published in this journal, which stress the importance of the interprofessional collaboration for achieving inclusive education (Botha \& Kourkoutas 2016; Hesjedal et al. 2015). As emphasised by a number of studies, it is important to be aware of the risks of the labelling and diagnosing that may occur within the collaborative process. We argue that interprofessional collaboration is not just an innocent stop on the path towards inclusion but that collaboration between educational psychologists, child psychiatrists, teachers, and other professionals may also produce and transmit diagnoses and labels that may hinder the objective of 
inclusion. Our analysis of educational psychologists' critique of child psychiatry, aligns with several previous studies on psychopathology and the relationship between diagnosis, labelling, education, and the role of teachers. Furthermore, our analysis aligns with 'post-conventional' approaches to understanding critical educational psychology (Goodley 2017) and thus to the reframing of "the disabled body along the lines of capacity, potential, interconnedcction and possibility" (Goodley 2017, 45). The present study problematises the influence of psychopathology in interdisciplinary collaboration. This influence might have consequences for the possibility of the development of critical psychological approaches, an approach that in its thereoretical assumptions is closer to the theories of situated practice in inclusive education.

Our use of 'psychopathology' refers to studies by Valerie Harwood and Julie Allan (Allan \& Harwood 2014; 2016; Harwood \& Allan 2014), who characterise psychopathology as related to "the range of mental disorders used in schools and education and to the discourses and practices tied to psychopathology that allow significant proportions of children and young people to be identified and treated as mentally ill" (Harwood \& Allan 2014, p.1). An essential aspect is the way psychopathology connects to societal risk factors: "Psychopathology marks out subjects as either having or being at risk of mental disorders" (2014, p.7). Through empirical studies in Australia, the UK, and the USA, Harwood and Allan argue that drugs and medicalisation are increasingly applied to children who have been deemed at risk. In a literature study including statistics on ADHD and childhood disorders in Brazil, Australia, the UK, and the US, they argue that the scientific and educational literature tends to ignore issues such as class, gender, and racialisation when it comes to understanding and producing disorders (Allan and Harwood 2016, p.185). In Denmark, we observe similar tendencies regarding psychopathology in the aforementioned increase in the number of students referred to mental health services.

The present study relates thematically to a range of other studies from the past two decades that combine education and the diagnosing and labelling of students, particularly with regard to the potential of inclusive education. These studies point to the international increase in the use of medical models in the professional language in schooling, despite the contemporary desire to achieve inclusive education (Lloyd and Norris 1999; Lloyd, Stead and Cohen 2006). In their global studies on the production of ADHD in education, Lloyd, Stead, and Cohen touch upon how the medicalisation of education, as evident in the ADHD discourse, may disempower teachers (Lloyd, Stead and Cohen 2006 p.3). A special issue of International Journal of Inclusive Education (2008) analyses these issues, addressing the connection between medicalisation and school professionals as well as calling for greater understanding of what takes places in the practice of schooling and teachers' pedagogy. "Some important questions must be asked and stronger resistance to the medical invasion of the educational field must be mounted. It is time for educators to reclaim expert status in the field of education" (Graham 2008a, pp.1-2). Graham argues in a literature review that understanding the relationship between diagnosing and schooling requires analysis of how the structure of schooling may be implicated in the production of students as disorderly subjects and may thus actually be exclusive (Graham 2008b). As Graham puts it: 
"In the end, perhaps the most important breakthrough with regards to researching the

'ADHD' phenomenon is that the notion may actually help to elucidate the pathologies within schooling; highlighting schools and systems that subscribe to the notion of being inclusive, yet in reality engage in practices that are anything but.” (p.28)

A number of studies have contributed to our understanding of how diagnosis in general and diagnosis of ADHD in particular are socially constructed and how this diagnostic production relates to the function of inclusion and exclusion within education (Bailey 2010, Graham 2006; 2008a; 2008b; Lloyd \& Norris 1999; Lloyd et al. 2006; Stead \& Lloyd 2008). Some studies relate in particular to the role of schooling and the teacher in the labelling of students (Armstrong 2014; McMahon 2012; Isaksson et al. 2010; Orsati \& Causton-Theohasis 2013; Hjorne and Saljo 2004; Freedman 2016), and some studies analyse how diagnoses are perceived by children who are medicated or situated in special institutions (Exley 2008; Graham 2016; Skovlund 2014). In their study of the medicalisation of the behaviour of youth from disadvantaged areas in Scotland, Allan and Harwood reveal professional deploy strategies to halt or disrupt the slide into diagnostics (Allan \& Harwood 2014, p.413).

The present study contributes to the existing knowledge concerning psychopathology in education by presenting a case of how collaboration between educational psychologists and child psychiatrists tends to reproduce a diagnostic understanding of students. We also question how diagnostic knowledge is transferred to teachers' practice.

\section{Methodology}

We present an empirical study of the discursive battle for positioning between the domains of psychiatry and educational psychology, relative to notions of inclusion and exclusion as well as the educational organisation of teaching. The empirical portion of this article draws upon a project implemented in collaboration with Copenhagen Municipality's Children and Young People's Services Department in 2013-2015. The project sought to develop interprofessional collaboration to encourage inclusion in the school system. Specifically, the project focused on interprofessional collaboration between psychologists and psychiatrists when at-risk children were referred to professionals for examination and testing. Eight municipal educational psychologists were interviewed for the project. Four were from educational psychological counselling within the 'normal range' (i.e. the department that covers students who will ideally return to mainstream education in state schools), and four were psychologists from the 'specialised area' (i.e. the department responsible for advice relating to students who have been deemed eligible for special schools) in Copenhagen Municipality. Both sections of the department are legally obliged to cooperate with the schools on achieving the inclusion agenda in the Danish school system. The two leading psychologists from both areas were included among the interviewees. In both areas, there is external interdisciplinary collaboration with the children's psychiatric ward at Bispebjerg Hospital concerning examinations of students with diagnoses or deemed diagnosable. In the current project, educational psychologists were interviewed concerning their experiences of collaborating with psychiatrists who examined students, documentation that reported on examinations, the network 
meetings concerning students, and the roles of the two groups of professionals when it came to future placement of students in either mainstream schools or special schools.

\section{Theoretical position}

This study draws upon Michel Foucault's work and thus on the assumption that neither psychology nor psychiatry reflect a neutral scientific position. They represent discursive forms of power, producing different kinds of truth about the child who is assessed as problematic (Foucault 1992). The relationship between discourses is influenced by political and economic rationales and cannot be reduced to a discussion of 'true knowledge' about the child but is instead part of a discursive battle in which one thing is included as true knowledge while another is excluded. The British sociologist Nikolas Rose uses the term 'knowledge regimes' (Rose 1998, 115) to emphasise that scientific discourses are components of truth relative to specific objects - in this case, the children. Use of the term 'knowledge regimes' stresses the crucial Foucauldian point that discourses exercise power. For example, educational psychological assessments and child psychiatric examinations offer various forms of legitimacy, each of which are influenced by external rationales and logics. Truth regimes, such as those evident in the battles between psychology and psychiatry, in line with Foucault's position (Foucault 1992), relate to societal, historical, and present-day battles, tensions, and influences. Today's discursive battles are influenced by school and community rationales, as can be seen, for example, in the education policy agendas that seek to maximise improvement of students' academic skills and accomplishments (Hamre 2014; Kousholt and Hamre 2016). Collaboration between psychologists and psychiatrists concerning students' difficulties can correspondingly be analysed as cultural and historical changes in the ways in which children's problems are described. In our understanding of 'diagnosis', we align ourselves with positions within disability research that define diagnosis as an identity construction in which human deviation is pathologised (Corker and Shakespeare 2006; Tremain 2015). Furthermore, this theoretical position is epistemologically in line with the critical positions presented in the above section on psychopathology in education.

\section{The empirical study}

The analysis in this study takes a phenomenological methodological approach to the interviewed psychologists, attending to their perspectives and focusing on their narratives and experiences of external collaboration with psychiatrists. Each semistructured interview was scheduled to last for 45 minutes. The study included four phases: 1) completion and recording of the eight interviews, 2) transcription of the interviews, 3) construction of key issues across the individual interviews, 4) analysis of issues by the article's coauthors. The first author of this article conducted the first two phases. The third and the fourth phase were completed through discussions among all three researchers. Whereas the first phase approached the interviews phenomenologically, the third and the fourth phases sought to construct patterns across the individual interviews. Drawing upon Foucault's constructivist approachkey issues were constructed. These key issues express dimensions of the discourse on educational psychology. The discourse is perceived through the psychologists' self-perceptions. This article uses some statements from the interviews as key quotes 
that represent various dimensions of the discourse. These key issues and key quotes involve: troubleshooting culture, collaboration with child psychiatry, and criticism of diagnostic culture. Combining the oral narratives raised in the eight qualitative interviews with Foucault's notion of discourse thus gives us the opportunity to observe the individual narratives as a whole or - drawing upon the section above - as a knowledge regime, representing a particular gaze upon the child and the collaboration with child psychiatrists. Rather than applying any one method of discourse analysis, we apply a discourse or knowledge regime to construct a pattern across the interviews. An early version of the analysis of the empirical data was sent to the two leading municipal psychologists for potential comments.

\section{Analysis}

The analysis is divided into three subsections. The first subsection concerns the educational psychologists' self-reflections on their practice of maintaining a 'troubleshooting culture' and on their experience of psychiatric dominance in the collaboration. The second subsection focuses on the dilemmas psychologists face when transferring diagnostics knowledge to teachers and educational contexts, including school psychologists' ambivalent attitude towards diagnoses. The third subsection relates to the psychologists' more general criticism of diagnostics. These subsections are not strictly divided between their thematic perspectives but instead aim to illuminate how various aspects of psychopathology are present in the collaboration between the professions.

\section{A troubleshooting culture and a psychiatric dominance in the collaboration}

Copenhagen Municipality's educational psychologists aim to move away from a troubleshooting culture when it comes to the examination of students assessed as problematic. The psychologists are professionally acknowledged for their skills and expertise with regard to testing children, yet as the managing psychologist notes, it is not necessarily testing that produces the best results as far inclusion is concerned. Within psychology culture, there are thus relics of an individually oriented approach, which raises the question of how the profession can move away from an individualised culture when this individualisation is present in in the diagnostic culture of the psychiatrists with whom they collaborate. According to the managing psychologist, the individually oriented understanding of students' difficulties is evident in educational psychologists' written assessments, which tend to reproduce the diagnostic understandings of the psychiatric assessments:

“They shouldn't write on the basis of a psychiatric report. They can refer to it and conclude something from that ... There's a tendency that the more you describe the child's problems and how difficult it is, the greater the possibility there is to get support and to get the child into something else." (Lead psychologist, normal range)

Previously a psychiatric diagnosis was required if a student was to be referred to special education.

"It's a running joke that the psychological assessment isn't read at the school. The paper should be used in practice. It needs to be a snapshot that can be used by the teacher, and we need to think about what we're doing. Previously, it's just been used to exclude children, the old expert knowledge - now there's more shared responsibility." (Psychologist D) 
Psychologists still seem to be undertaking the transition from a troubleshooting culture, in which psychologists are experts who communicate knowledge to teachers. The psychologists' selfreflections suggest a tendency within their culture to reproduce diagnostic explanations in assessments as a result of a psychiatric dominance in the interprofessional collaboration. The psychologists often describe this collaboration as hierarchical, and some psychologists explicitly criticise this hierarchy:

"For me, it's all about who has the power of definition, and it's about professional imperialism.” (Psychologist F)

Although the nature of the collaboration between psychologists and psychiatrists has changed over time, such statements give the impression that power relationships remain unequal and that battles are still being fought. This applies to collaboration surrounding the understanding of a student's difficulties as well as in cases in which child psychiatry has referred students to specific special educational services in connection with an examination:

"Years ago, we might have a statement that read: "He needs a special school" and so we thought, stay away from it ... I can't point to concrete measures, we need to create collaboration. We also encounter changes in psychiatry. We're not as far apart today. There are, of course, descriptive diagnoses that you give, such as Asperger's, right? It's not so much the diagnoses but the descriptions. We've talked ourselves into each other, and we can move forward." (Psychologist D)

There is thus talk of a paradigm shift between professions, in which network meetings result in a greater degree of common understanding between the two professions than was previously the case (Psychologist D). When it comes to collaboration concerning a child, psychiatry has the authority to convene a network meeting on how to proceed, and although it is no longer a legal requirement, the culture of collaboration still emphasises psychiatric assessment as the basis for referral to special entitlements. Psychiatry holds a privileged position in the collaboration. This is also the case with student assessment files, into which educational psychologists have tended to insert diagnostic knowledge.

\section{Psychologists as mediators of diagnostic knowledge in educational contexts}

Psychologists usually convey the diagnostic knowledge into educational contexts and translate diagnostic understandings in dialogues with school teachers. This illuminates an ambivalent aspect of the collaboration between psychologists and psychiatrists, one that psychologists handle pragmatically.

"When the children are described (diagnosed) at one of the centres, it's not usually the psychologists who do things. It seems a little strange that it's often the psychiatrist who says what needs to be done when it's still the psychologist who needs to pass it on to the special school." (Psychologist E) 
The psychologists are more committed to the inclusive agenda within educational psychology, which implies moving away from the individually oriented view. This forces psychologists to transition from a mono-professional expert advisory role towards a more multidisciplinary consulting role, which requires them to take the initiative for context-based solutions in collaboration with the schools. There has not been a similar questioning of the expert role of psychiatry. Psychiatrists are not committed to the schools' inclusive agenda in the same way but have increasingly been able to legitimise the investigation of students' difficulties as a scientific, objective overview of the analysis - independent of educational or political agendas. Though not legally obliged to follow the inclusive agenda, psychiatrists' positioning relative to psychologists in educational settings thus influences the educational agenda. As we have seen, psychiatrists indirectly influence schooling through the transferability of diagnostic knowledge to the teachers, whereas the psychologists' role risks being reduced to that of mere mediators. The existence of psychopathology in the school system is thus strengthened by the transfers between the different professionals.

The psychologists' narratives highlight several issues that can arise when diagnoses are rendered actionable in educational contexts. This applies, for example, to psychologists' reflections regarding the use of templates in educational psychological examination and testing. The presence of templates in the files means that psychiatric problem understandings can come to dominate the documentation. One psychologist in the general area, Psychologist A, calls for a different approach to the importance of diagnostic documentation in the educational context. For example, there could be a field called "a new possible understanding of the child," making it possible to complete the follow the template more in relation to the child's onward journey in the school context. There are, in fact, major differences between the individual psychologists' approaches to this: While some psychologists reproduce a very brief diagnostic background, others contain nuanced descriptions of the student's challenges. In some cases, the diagnostic knowledge leads to specific predictions about the child's future, which are used to demand specific kinds of support:

"I've experienced that they [the psychiatrists] write that children with ADHD are at increased risk of getting into crime and abuse, so they write that if the child doesn't receive the right support, he or she will develop risk behaviour. I wondered why they'd written it. It's something else if they're specific and, for example, write about a need for visualisation, or social training, so it's usable in a completely different way." (Psychologist B)

The psychologists generally are critical of the far-reaching significance of diagnostics and documentation. According to the psychologist who leads the special needs education area in the municipality, psychiatrists should stick to describing the problem and not make specific recommendations concerning educational practice:

"It may certainly be a challenge not to just automatically give a child a special entitlement because it appears in the conclusion of the analysis ... And there, we've influenced them so they shouldn't point to a specific entitlement in their conclusion - 
either in social management or segregated entitlements." (Head of special area management ${ }^{1}$ ).

Though this obviously concerns professional demarcations, from an analytical perspective, this may appear to be a disruption of the production of psychopathology in the collaboration, since the psychiatrist's knowledge is hindered from legitimising a special entitlement for the child. When diagnostic explanations dominate the investigation of a child's difficulties it is a matter professional hierarchy. As noted above, these examples highlight the potential problems that can occur when descriptive knowledge - as a diagnostic problem understanding - is transferred into practical knowledge that can be rendered actionable in a specific educational situation. This may also be an aspect of psychopathology's role in education, blurring the lines between descriptive knowledge as diagnosis and teachers' practical knowledge in educational situated contexts.

\section{The stigmatising and prescriptive functions of diagnosis}

The criticism raised by psychologists sheds light on how psychopathology can work through the stigmatising and prescriptive functions of diagnosis. In their descriptions of collaboration with psychiatry, the psychologists criticise the importance that diagnoses have been granted in relation to educational practice and individual children. This criticism covers the psychologists' view of themselves as professionals and a general critique of how the increasing number of diagnoses has taken control within both special and general pedagogy.

"It's rather stigmatising to get a diagnosis, but I try to tell the child, 'of course you're more than that.' It's not within him, it's with him. From time immemorial, the medical world has been closer to the natural sciences. People know that you haven't looked inside the brain in question, but it makes an impression when a child is diagnosed with ADHD." (Psychologist A)

There is a pronounced criticism of the rush to diagnose because the diagnosis is claimed to oversimplify the difficulties surrounding a child.

"It's like, if you have a diagnosis, you have a psychological explanation, then you have a pedagogical tool, and the world bloody well isn't designed like that, and there it all collapses for this system." (Psychologist F)

This quote highlights an aspect of psychopathology since it expresses the constructed connection between the stigma of the diagnosis and educational actions. It is thus a critique of the transferability of diagnostics into educational practice. While some psychologists criticise this transferability, others emphasise the usefulness of diagnoses as snapshots, if not as explanations or descriptions of the child as a whole (Psychologist C). This is not an easy task, however, because diagnoses tend to circulate among professionals within the school system. As expressed by another psychologist, 'diagnoses' such as ADHD develop lives of their own in the school context, even

\footnotetext{
${ }^{1}$ The Children's Centre Copenhagen (special area of management) seeks to help evaluate the statements, and when there are examples in which interventions relate to specific special schools or treatment, this is criticized.
} 
prior to an examination (Psychologist D). A related issue is how professionals use diagnostic explanations prescriptively in the process of defining educational goals and actions to help children forward. One psychologist working within the normal range explains:

"For example, I have a child with infantile autism who's to be included in the school. While the nursery school is already worried about how he'll cope with the $5^{\text {th }}$ grade, I try to get them to think just three months ahead. Then schooling comes into focus much more clearly." (Psychologist A)

There are several issues here. This is a situation in which, on the one hand, the diagnosis is granted almost prophetic significance while, on the other hand, a one-sided focus on the school's goals and expectations can inadvertently reinforce its diagnostic focus on the child. This illuminates the prophetic character of psychopathologisation relating to the assessment of students as individuals. Psychologists identify several criticisms in dealing with diagnoses, yet diagnoses are also recognised as a pragmatic necessity in understanding students' difficulties and in finding ways of helping individual students forwards.

\section{The inclusive agenda and the potentials of situated professionalism and critical educational psychology}

In this discussion, we question whether teachers situated professionalism and critical educational psychology may serve as a strong potential to produce to contrasts to the reproduction of psychopathology in the collaboration and in inclusive schooling in general. Our study on the reflections of educational psychologists seems to reflect that psychiatric diagnoses are often loosely transferred to psychology in interprofessional collaboration. More broadly, this relates to Allan and Harwood's discussion of psychopathology at school, which deals with the trend for viewing children and young people who exhibit risk behaviour in school as demonstrating psychiatric difficulties that call for medication (Harwood \& Allan 2014). Apart from the obvious increase in diagnosing, for instance for ADHD and autism, the strength of the diagnosis relies upon their pragmatic use in the interprofessional language, as seen in our analysis.. Nikolas Rose (2006) claims that, when it comes to understanding the human being, neuropsychology has gained ground relative to other explanatory models, such as psychology and philosophy. This perspective can explain psychologists' marked criticism of the trend towards diagnosis, but it can also explain the more pragmatic use of diagnostics as a useful tool in everyday life.

If the inclusion policy is realised in the coming years, this will involve children with diagnoses and with various learning difficulties becoming a permanent part of the mainstream learning environment. It is probably not a political objective to prevent any children from being referred to special institutions, but is hoped, as mentioned above, to halve the number of children referred to specialised institutions in the next few years, including by returning to mainstream schools some of those who are already excluded. Those children who until now have not really fit into the general school learning cultures have in principle had to be accommodated in more exclusive special educational learning arrangements (special schools and special classes). This can no longer be 
readily maintained. Thus, for the first time in decades, school learning environments in Denmark must actually relate to the children who cannot easily be accommodated in mainstream school learning environments because these children are now permanent members of the group of children. This means that the children's group will consist of a greater diversity of students and that pedagogy and teaching cannot be directed predominantly towards 'the majority' but must increasingly be adapted to diversity.

In order to implement inclusion as a new social policy agenda, it is necessary to examine how diversity in the school can be educationally and didactically managed for the future. The concept of universal inclusion (Norwich 2013), which has characterised the Danish debate, holds that the traditional pedagogical response is for differentiated teaching (Tomlinson 2003; HedegaardSoerensen \& Penthin Grumloese). In policy and research, the case is largely made that disability should not be understood in terms of individual barriers and experiences but instead as a product of structural exclusion. Barriers are not individual but are embedded in organisational structures and pedagogical practice (Shakespeare 2013; Norwich 2013).

Moderate stances in the debate on inclusion (Shakespeare 2013) recommend the Nordic relational model as a basis for change in inclusive learning environments. Barriers here are seen as both structural and individual. This forms a starting point for discussing the role of individual barriers and of diagnosis - in teaching and pedagogical strategies. The analysis in the present article calls for discussions concerning the relationship between students' medical diagnoses and teachers' practice. Empirical research into diagnosed students in learning environments across mainstream and special learning environments (Hedegaard-Sørensen \& Tetler 2011;2016) confirms that teaching and pedagogy are not generated by psychiatric knowledge of diagnostics. The idea that teaching in special and mainstream schools is diagnostically prescriptive is described as a theoretical illusion. Even among staff in special schools who advocate specific knowledge and specialised teaching, teaching is understood primarily as a pedagogical task involving pedagogical and didactic reasoning and reflection. Teachers are "situated professionals" (Hedegaard-Sørensen and Tetler 2016; Hedegaard-Sørensen \& Tetler 2011), who draw upon a multitude of theoretical perspectives and combine these depending on the pedagogical situation in question. Knowledge about individual barriers (and assumed diagnoses) is only part of this didactic reasoning and reflection. Teaching is first and foremost a pedagogical task and cannot be understood in terms of evidence-based practice (Biesta 2012) or - we may add, drawing upon the present analysis - in terms of psychiatric knowledge.

The challenge for school policy in the coming years is thus to support the collaboration and building of strong partnerships between different groups of professionals (psychiatrists, psychologists, teachers from special schools, and teachers in mainstream schools) (Botha and Kourkoutas, 2016). The key challenge is to determine how children can be treated differently without resulting in stigmatisation. This collaboration will hopefully lead to professional transformation and the creation of new knowledge concerning how to combine divergent theoretical perspectives in the teaching practice (Edwards et al. 2009). 
Some of the challenges involved in educational psychologists' collaboration with child psychiatrists and the hegemonic tendencies of the two professions can in part be explained by a weak professional self-confidence among educational psychologists and an apparently strong but traditional diagnosis culture among child psychiatrists. More theoretical attention to the international 'critical educational psychology' could be a means of enhancing cooperation with school psychology practitioners on the one hand and - difficult though it may appear - supporting a more 'critical psychiatry' in Denmark on the other.

A 'critical psychiatry' inspiration may be found in the aforementioned statement that "The past 30 years have produced no discoveries leading to major changes in psychiatric practice," which the authors continue by arguing that "Embracing a social paradigm could generate real progress and, simultaneously, make the profession more attractive" (Priebe, Burns \& Craig 2013, p. 319). Similarly, a 'critical educational psychology' inspiration can be identified within Tom Billington's three constructs, 'mental space', 'relational space', and 'relational being' (Billington 2014). Billington (2017) also notes the need for a 'critical neuroscience' (Billington 2017) as a possible link between the psychiatric and psychological professions in their collaboration in praxis.

In the Danish context, such reflections on educational psychologists within PPR and their collaboration with child psychiatrists in the coming years are highly relevant because the National Departments of Education and Social Affairs have just released a sizable tranche of funding (by Danish standards) dedicated to developing new strategies within PPR, focusing on earlier and more preventive initiatives targeting vulnerable children and adolescents, with the aim of reducing the need for specialised assessment and medication (Socialstyrelsen Pulje: Investering i den tidlige og forebyggende indsats i PPR, 2017).$^{2}$ This is a political initiative that itself prompts changes in the relative positions of psychiatrists and educational psychologists as well as offers a golden opportunity for reviving educational psychology with a critical twist in Denmark.

\section{Conclusion}

This article's empirical approach has largely taken the perspective of psychologists in the collaboration with the psychiatrists. The study is based on interviews and reflect a discursive pattern in educational psychologists' views on interprofessional collaboration. Aligned with the ambitions in post-conventional school psychology (Goodley 2017; Williams, Billington, Goodley \& Corcoran 2017), the study has a narrow focus on self-perceptions rather than on new practices in collaborative processes. This study highlights the need for further research into post-conventional approaches in collaborative practice in inclusive education. However, the study points at the educational psychologists' desire to work more inclusively, in accordance with statutory intentions. A number of factors feed into this work: the desire to eliminate a troubleshooting culture, less hierarchy between the two groups, less reverence for psychiatrists' problem descriptions in the documentation, and an expansion of psychologists' role as facilitators in the school context. Based on our analysis, we suggest it is important that the diagnosis is envisaged within the teacher's

\footnotetext{
${ }^{2}$ (DK: “... at nedbringe mistrivsel blandt sårbare og udsatte børn og unge, så færre får behov for en specialiseret indsats og eventuel medicinering.").
} 
didactic framework of understanding, whether in general or special education. In other words, we argue that the inclusive mindset implies a need for diagnosis and problem descriptions in general to be related to the context of teachers' educational practice, rather than for the diagnosis to be drawn upon or for textbook diagnostic knowledge to be reproduced. Additional interviews with child psychiatrists could have supplemented the analysis with psychiatrists' views on interprofessional collaboration.

Our analysis has highlighted some of the dilemmas related to inclusive schooling in Denmark. The children brought into mainstream classes by the inclusion policy tend to be characterised by generalised psychiatric behavioural descriptions such as: 'disorderly or risky behaviour, 'makes careless mistakes in schoolwork', 'does not follow instructions', and 'does not care for mentally strenuous tasks', i.e. descriptions often related to children diagnosed with ADHD. In the case of children diagnosed with autism, typical behavioural descriptions feature: 'needs a clear and structured framework', 'needs special attention in unstructured situations', and 'needs one-to-one teaching'. Since it is impossible to refer these children to other educational settings, it is difficult to identity suitable educational results. When teachers allow their everyday teaching practices to be guided by the diagnostic manual of behavioural characteristics, it likely creates more peace and order in the classroom. As we have argued, however, this is not a sustainable solution since it represents a challenge to the policy of genuine inclusion of differently abled students. The efforts to achieve inclusion depend upon two, interrelated strategies. We suggest a new orientation for daily educational life, one that emphasises a psychological learning perspective that transcends psychiatric behavioural characteristics and leaves troubleshooting culture behind. This requires a new didactic understanding of the organisation of teaching and professional learning goals, an understanding that cognitively encounters the 'new students' in the classroom.

Psychiatric diagnostics have long been an integral part of the educational system. The inclusive agenda implies a desire on the part of teachers, educators, and politicians to rethink how diagnoses are produced and transferred in schooling. The present study has questioned how the transfer of diagnostic knowledge from educational psychologists to teachers problematises the school system's role in the (re-)production of psychopathology. Achieving inclusive education requires an awareness of the structures of exclusion. This article has touched upon the need to focus on how diagnostic language and practice are constructed in interprofessional settings and risk interrupting the inclusive agenda. In the process of promoting an inclusive agenda within schools and among the professionals collaborating in it, critical psychiatry, critical educational psychology and situated learning pratices can produce necessary insights in this promotion.

\section{List of references}

Allan, J. \& Harwood, V. (2014). Medicus interruptus in the behaviour of children in disadvantaged contexts in Scotland, British Journal of Sociology of Education, 35:3, 413-431. 
Allan, J. \& Harwood, V. (2016). The risk factors for psy-diagnosis? Gender, racialization and social class. In E. Peterson \& Z. Miller (Eds) Interrupting the psy-disciplines in education. Springer, pp. 185-202.

Armstrong, D. (2014) Educator perceptions of children who present with social, emotional and behavioural difficulties: a literature review with implications for recent educational policy in England and internationally, International Journal of Inclusive Education, 18:7, 731-745.

Bailey, S. (2010) The DSM and the dangerous school child, International Journal of Inclusive Education, 14:6, 581-592.

Biesta, G. (2012). Giving Teaching Back to Education: Responding to the Disappeareance of the Teacher. Phenomenology \& Practice 6 (2): 35-49.

Billington, T. (2017): A future? Why educational psychologists should engage with a critical neuroscience. In: Williams, A., Billington T., Goodley, D. \& Corcoran, T (Eds.): Critical Educational Psychology. West Sussex: Wiley-Blackwell

Billington, T (2014): Towards a Critical Relational Educational (School) Psychology. In: Corcoran, T. (Ed.): Psychology in Education. Critical Theory Practice. Rotterdam SensePublishers

Booth, T., and M. Ainscow, eds. (1998). From Them to Us: An International Study of Inclusion in Education. London: Routledge.

Botha, J. \& Kourkoutas. E. (2016). A Community of Practice as an inclusive model to support children with social, emotional and behavioural difficulties in school contexts. International Journal of Inclusive Education. Vol. 20. No. 7. (784-799).

Bracken, P. \& Thomas, P. (2001): Postpsychiatry: A new direction for mental health. BMJ, 322:724 
Bracken, P. Thomas P., Timimi, S. Asen, E., Behr,G., Beuster, C., Bhunnoo, S., Browne, I., Chhina, N., Double, D., Downer, S., Evans, C. Fernando, S., Garland, M.R., Hopkins, W., Huws, R., Johnson, B. Martindale, B. Middleton, H., Moldavsky, D., Moncrieff, J., Mullins, S., Nelki, J. Pizzo, M., Rodger, J. Smyth, M. Summerfield, D.,Wallace, J. \& Yeomans, D. (2012): Psychiatry beyond the current paradigm. The British Journal of Psychiatry, 201 (6) (430-434).

Corcoran, T, (Ed). (2014): Psychology in Education. Critical Theory Practice. Rotterdam: SensePublishers.

Corker, M. \& Shakespeare, T. (red.) (2006). Disability/Postmodernity: Embodying Disability Theory. London and New York: Routledge.

Edwards, A., H. Daniels, T. Gallagher, J. Leadbetter, and P. Warmington. (2009). Improving Interprofessional Collaborations: Multi-agency Working for Children's Wellbeing. London: Routledge.

Exley, B (2008). 'Staying in class so no one can get to him': a case for the institutional reproduction of ADHD categories and behaviours, International Journal of Inclusive Education, 12:1, 65-80.

Foucault, M. (1992). The Archeology of Knowledge. London: Routledge.

Freedman, J.E. (2016) An analysis of the discourses on attention deficit hyperactivity disorder (ADHD) in US special education textbooks, with implications for inclusive education, International Journal of Inclusive Education, 20:1, 32-51.

Goodley, D. (2017). Post-Conventionalism: Towards a productive Critical Educational Psychology, (pp. 43-51), In: Corcoran, T, (Ed). (2014): Psychology in Education. Critical Theory Practice. Rotterdam: SensePublishers.

Graham, L.J. (2006). Caught in the net: a Foucaultian interrogation of the incidental effects of limited notions of inclusion, International Journal of Inclusive Education, 10:1, 3-25. 
Graham, L.J., (2008a). ADHD and schooling: looking for better ways forward, International Journal of Inclusive Education, 12:1, 1-6.

Graham, L.J. (2008b). From ABCs to ADHD: the role of schooling in the construction of behaviour disorder and production of disorderly objects, International Journal of Inclusive Education, 12:1, 733.

Graham, L.J. (2015). 'I'm Happy with Who I Am': A Discursive Analysis of the Selfcharacterisation Practices of Boys in 'Behaviour' Schools. In O'Reilly, Michelle \& Lester, Jessica Nina (Eds.) The Palgrave Handbook of Child Mental Health. Palgrave McMillan, Basingstoke, Hampshire, pp. 519-538.

Gøtzsche, P.C. (2015): Does long term use of psychiatric drugs cause more harm than good? BMJ, 2015, 350:h2435.

Hamre, B. (2014). Optimization as a dispositive in the production of differences in Denmark schools, European Education, Vol. 45, no. 4, s. 7-25.

Hamre, B. (2016). Diagnosing, special education, and 'learnification' in Danish schools in: Nordic Journal of Social Research, Vol. 7, 65-76.

Harwood, V. \& Allan J. (2014). Psychopathology at School, Theorizing mental disorders in education, New York: Routledge.

Hedegaard-Sørensen, L. \& Penthin Grumloese, S. (2016). Larerfaglighed, inklusion og differentiering - padagogiske lektionsstudier i praksis [Teachers' knowing, Inclusive Education and Differentiated Teaching - Pedagogical Lesson Studies in practice]. København: Forlaget Systime.

Hedegaard-Sørensen, L. \& Tetler, S. (2011). Situated professionalism in Special Education Practice: Educating preservice teachers for special education/inclusive education. In A Practicum 
Turn in Teacher Education. Mattsson, M., Eilertsen, T.V. and Rorrison, D. (eds.). 113-130. Rotterdam: Sense Publishers.

Hedegaard-Sørensen, L \& Tetler, S. (2016). Evaluating the quality of learning environments and teaching practice in special schools. Journal of Special Needs Education, Vol. 31, Issue 2 (264278).

Hesjedal, E., Hetland, H., Iversen, A.C. \& Manger, T. (2015). Interprofessional collaboration as a means of including children at risk: an analysis of Norwegian educational policy documents, International Journal of Inclusive Education, 19:12, 1280-1293.

Hjörne, E. \& Saljo, R. (2004). "There Is Something About Julia": Symptoms, Categories, and the Process of Invoking Attention Deficit Hyperactivity Disorder in the Swedish School: A Case Study. Journal of Language, Identity \& Education, 3:1, 1-24.

Isaksson, J. , Lindqvist, R. \& Bergström, E. (2010) 'Pupils with special educational needs': a study of the assessments and categorising processes regarding pupils' school difficulties in Sweden, International Journal of Inclusive Education, 14:2, 133-151

Kousholt, K. \& Hamre, B. (2016). Testing and school reform in Danish education: An analysis informed by the use of 'the dispositive', The global testing culture: shaping education policy, perceptions, and practice (Ed. William C. Smith). Oxford: Symposium Books, Oxford Studies in Comparative Education; 1, Vol. 25, 231-247.

Langager, S. (2014). Children and youth in behavioural and emotional difficulties, skyrocketing diagnosis and inclusion/exclusion processes in school tendencies in Denmark, Emotional and Behavioural Difficulties, 19 (3), 284-295.

Lihme, B. (2017): Almindelighedens mulighed og betydning. In: Dansk Padagogisk Tidsskrift, 1 , 7-16.Lloyd, G. \& Norris, C. (1999) Including ADHD?, Disability and Society, 14, 505-517.

Lloyd, G., Stead, J. \& Cohen, D. (2006). Critical New Perspectives on ADHD. Oxon: Routledge. 
McMahon, S.E, (2012). Doctors diagnose, teachers label: the unexpected in pre-service teachers' talk about labelling children with ADHD, International Journal of Inclusive Education, 16:3, 249264

Norwich, B. (2013). Addressing Tensions and Dilemmas in Inclusive Education, Living with uncertainty. London and New York: Routledge.

Orsati, F.T, \& Causton-Theoharis, J. (2013) Challenging control: inclusive teachers' and teaching assistants' discourse on students with challenging behaviour, International Journal of Inclusive Education, 17:5, 507-525.

Priebe, S., Burns, T., \& Craig, T.K.J. (2013): The future of academic psychiatry may be social, In: The British Journal of Psychiatry, May 2013, 202 (5), 319-320.

Rose, N. (1998). Inventing Our Selves: Psychology, Power and Personhood. Cambridge: Cambridge University Press.

Rose, N. (2006). Disorders Without Borders? The Expanding Scope of Psychiatric Practice, Biosocieties, 1(4), $465-484$.

Shakespeare, T. (2013). Disability - Rights and Wrongs revisited. New York: Routledge.

Skovlund, H. (2014) Inclusive and exclusive aspects of diagnosed children's self-concepts in special needs institutions, International Journal of Inclusive Education, 18:4, 392-410.

Skrtic, T. M. (1999). Learning disabilities as organizational pathologies. In Perspectives on learning disabilities: Biological, cognitive, contextual, edited by Robert J. Sternberg and Louise Spear-Swerling. 193-226. Boulder, CO: Westview Press. 
Slee, R. (2011). The Irregular School: Exclusion, Schooling and Inclusive Education. London: Routledge.

Slee. R. (2013). How do we make inclusion happen when exclusion is a political predisposition? International Journal of Inclusive Education. Vol. 17. No 8, 895-907.

Socialstyrelsen (2017): Pulje: Investering i den tidlige og forebyggende indsats i PPR, [National Departments of Education and Social Affairs (2017). Group: Investing in the early and preventive efforts of Educational Psychological Consultancy].

Stead, J. \& Lloyd, G. (2008). 'ADHD: Creating continuing dilemmas for education in Scotland.' Scottish Educational Review. Vol 40 No 1 pp. $42-54$.

Tomlinson, C.A. (2003). Fulfilling the Promise of the Differentiated Classroom, strategies and Tools for Responsive Teaching. Washington: ASCD.

Tomlinson, S. (2013). The irresistible rise of the SEN-industry. Oxford Review of Education. Vol. 28. No. 3. June 2012, 267-286

Tremain, S. (2015). Foucault and the Government of Disability. Ann Arbor: University of Michigan Press. 